\title{
Dynamics of Nitroglycerin-induced Exhaled Nitric Oxide After Lung Transplantation: Evidence of Pulmonary Microvascular Injury?
}

\author{
Janos Gal, MD, PhD, ${ }^{\mathrm{a}, \mathrm{b}}$ Tamas Kovesi, MD, PhD, ${ }^{\mathrm{b}}$ David Royston, FRCA, ${ }^{\mathrm{b}}$ and Nándor Marczin, MD, PhD ${ }^{\mathrm{a}, \mathrm{b}}$
}

Background: In search of real-time molecular correlates to ischemia-reperfusion-induced lung injury, we explored the hypothesis that liberation of nitric oxide (NO) into exhaled breath after pulmonary microvascular bioconversion of nitroglycerin (GTN) is attenuated in clinical lung transplantation.

Methods: $\quad$ Exhaled NO was measured under basal conditions and after intravenous administration of GTN in patients undergoing lung transplantation. Patients undergoing routine cardiac surgery served as controls. Basal and GTN-induced exhaled NO was also measured in donors before retrieval and after implantation in recipients.

Results: The characteristic GTN-induced exhaled NO response observed in cardiac surgical patients before cardiopulmonary bypass and in lung transplant and multiple-organ donors was nearly totally abolished in lung transplant recipients. This response was also attenuated to a lesser degree in the routine cardiac surgery patients after cardiopulmonary bypass.

Conclusions: These results suggest a graded influence of time-factored complete and partial ischemia on GTN-induced evolution of NO into exhaled breath, providing biochemical evidence for a degree of microvascular injury, which can be monitored non-invasively at the bedside. J Heart Lung Transplant 2007;26:1300 -5. Copyright $\odot 2007$ by the International Society for Heart and Lung Transplantation.

The high incidence of characteristic histologic features of diffuse alveolar damage in transbronchial biopsies, the prevalence of severe allograft dysfunction termed "primary graft failure," and the high early mortality after lung transplantation all suggest that the current practice of lung transplantation inflicts severe damage to the lungs judged as "ideal" for transplantation. ${ }^{1-3}$ This damage is difficult to predict with the current acceptance criteria and monitoring is currently centered on functional consequences on gas exchange and lung mechanics. The tremendous progress made on the basic science of lung ischemia/reperfusion (I/R) injury now offers additional novel approaches for molecular diagnostics at the bedside and therapeutic break-

From the ${ }^{\mathrm{a}}$ Department of Anaesthetics, Pain Medicine and Intensive Care, Division of Surgery, Oncology, Reproductive Biology and Anaesthetics, Faculty of Medicine, Imperial College London, London; and ${ }^{b}$ Royal Brompton and Harefield NHS Trust, Harefield Hospital, Harefield, UK.

Submitted February 10, 2007; revised June 11, 2007; accepted September 12, 2007.

Supported in part by the British Heart Foundation and the Medical Research Council (to N.M.)

Reprint requests: Nándor Marczin, MD, Department Anaesthetics, Harefield Hospital, Hill End Road, Harefield, Middlesex UB9 6JH, UK. Telephone: +44-1895-453-804. Fax: +44-1895-828-900. E-mail: n.marczin@imperial.ac.uk

Copyright (c) 2007 by the International Society for Heart and Lung Transplantation. 1053-2498/07/\$-see front matter. doi:10.1016/ j.healun.2007.09.033 throughs targeting these molecular players in the clinical arena. ${ }^{4,5}$

NO is undoubtedly one of the master regulators of nearly all aspects of pulmonary microvascular function from vasodilation to lymphocyte kinetics. ${ }^{6,7}$ Characteristic changes have been uncovered in the activities of the NO-cGMP axis in association with the development of I/R injury, and several strategies to preserve this pathway have shown substantial organ protection in model systems $^{8-10}$ and clinical benefit in humans. ${ }^{11-13}$ However, recent failures of inhaled NO therapy to prevent and treat reperfusion injury in the clinical setting may suggest that our understanding of NO dysfunction at the bedside is incomplete and perhaps some of our therapeutic strategies may be flawed. ${ }^{14,15}$

Analysis of NO in exhaled breath is a powerful non-invasive approach in molecular assessment of lung metabolism. For instance, exhaled NO in asthma is now well recognized both by regulatory authorities and major respiratory societies, thereby changing diagnostics, monitoring and treatment. ${ }^{16,17}$ Similar "inflammometry" focusing on this important "gasotransmitter" in mechanically ventilated patients has also been proposed, ${ }^{18,19}$ based on the notion that exhaled NO reflects the dynamism of NO production and consumption in the lung. ${ }^{20-22}$

We have previously explored the influence of lung transplantation on exhaled $\mathrm{NO}$ and also proposed a pharmacologic tool as a metabolic test of the pulmo- 
nary microvasculature based on liberation of NO to alveolar air during pulmonary metabolism of intravenous nitroglycerin. ${ }^{18,23}$ We have also established the influence of a clinical form of relatively short and incomplete lung ischemia-reperfusion injury on both basal and GTN-induced exhaled NO, such as that occurring during routine cardiac surgery, utilizing cardiopulmonary bypass (CPB). ${ }^{24}$ In this study we sought to establish the influence of more prolonged and total lung ischemia and reperfusion on these parameters during lung transplantation.

\section{METHODS}

\section{Study Design}

The study design included two separate studies. The objective of the first study was to characterize GTNinduced exhaled NO in lung transplant recipients. Patients undergoing routine cardiac operations utilizing CPB served as controls.

The second phase of the study targeted measurements both in the donors at a distant hospital before organ procurement and, subsequently, in the recipient after implantation of the same lungs after reperfusion. The study was conducted in accordance with the guidelines approved by the ethics committee of our institution and informed consent was obtained from the participants.

\section{Patients}

Characteristics of the control patient population and their anesthetic and surgical management have been described previously. ${ }^{24}$ This group consisted of 10 patients undergoing myocardial revascularization (coronary artery bypass grafting; CABG) with CPB.

The lung transplant group included 10 patients undergoing heart-lung transplantation or sequential bilateral lung transplantation for end-stage lung disease due to cystic fibrosis or pulmonary hypertension. Lungs were procured from cadaveric donors (mean age 30 years, 8 men and 2 women) with either traumatic head injury, sub-arrachnoidal hemorrhage or brain tumor. The main preservation technique was core cooling. A complete cardiac team and necessary perfusion equipment were deployed to the distant donor hospital. After full heparinization, the donor was placed on $\mathrm{CPB}$ and cooled to $10^{\circ} \mathrm{C}$. The lungs were also cooled by topical ice during the cooling period, and were procured without any further flush perfusion. Total ischemia time was $214 \pm 18 \mathrm{~min}$ utes. One recipient fulfilled the clinical criteria of primary graft dysfunction and subsequently developed sepsis and had a protracted ICU stay. The $\mathrm{PaO}_{2} / \mathrm{FIO}_{2}$ ratio on admission to the ICU for the cohort was $357 \pm 60 \mathrm{~mm} \mathrm{Hg}$.

\section{Chemiluminescence Analysis of NO and Data Analysis}

Breath-to-breath measurements of NO concentrations in the lower airways were performed using a real-time, computer-controlled, integrated system (Series 2000 and 3000; Logan Research, Ltd.) with ventilation standardized for inspired gas $\left(100 \% \mathrm{O}_{2}\right)$, tidal volume $(5 \mathrm{ml} / \mathrm{kg})$, respiratory rate (10/min) and inspiratory:expiratory ratio (1:3), with positive end-expiratory pressure (PEEP) at zero for the duration of the measurement epoch, as described elsewhere. ${ }^{18,24,25}$ Statistical comparison among the groups was performed using analysis of variance (ANOVA) and Student-Neuman-Keuls post hoc tests. Statistical significance was accepted at $p<0.05$.

\section{RESULTS}

Chemiluminescence analysis of exhaled NO in most ventilated patients revealed a characteristic breath-tobreath pattern. We previously reported that this characteristic trace is not always seen after lung transplantation. ${ }^{18}$ Figure $1 \mathrm{~b}$ shows one such measurement in a patient whose exhaled NO was undetectable and the trace largely represents background noise. A similar trace was obtained in 8 of our 10 lung transplant patients in this series. A fraction of the lung transplant patients ( 2 of 10 patients in the current study), however, exhibited a similar NO profile to those undergoing routine cardiac surgery. Figure 1c shows a representative trace from one of these patients.

We have also reported the pattern of GTN-induced increase in exhaled $\mathrm{NO}$ in patients undergoing routine heart surgery. ${ }^{24}$ As a reference, Figure 1a depicts such a response in a patient undergoing bypass surgery before $\mathrm{CPB}$. Figure $1 \mathrm{~b}$ and $\mathrm{c}$ demonstrates that there is very little change in exhaled NO after GTN administration in lung transplant recipients when measured approximately 1 hour after reperfusion during hemostatic and hemodynamic stability. This response was not only missing in those patients whose basal NO was undetectable (Figure 1c), but it was nearly abolished even in those who demonstrated normal basal exhaled NO (Figure 1c).

Figure 2 shows summary data on basal and GTNinduced exhaled NO levels (Figure 2a: area under curve; Figure 2b: peak levels). When compared with control levels in routine cardiac patients (CABG PRE), basal levels of exhaled NO (both peak and area under curve) were smaller after lung transplantation (TX). Remarkably, GTN-induced exhaled NO (measured as either peak or area under curve) was virtually eliminated in the lung transplant group $(0.4 \pm 0.3$ vs $6.0 \pm$ $2.1 \mathrm{ppb}$ and $2.4 \pm 4.6 \mathrm{vs} 113.6 \pm 46.7 \mathrm{ppb}$, respectively). Importantly, the influence of GTN bolus on systemic blood pressure was comparable to coronary artery bypass grafting (CABG; $38 \pm 3$ and $9 \pm 2 \mathrm{~mm} \mathrm{Hg}$ decrease in systolic and diastolic arterial pressure, re- 
spectively). GTN-induced exhaled NO was also reduced after bypass (CABG POST, Figure 2), but not to the same degree as after lung transplantation $(2.2 \pm 0.7$ and $26.4 \pm 7.3 \mathrm{ppb}$ for peak and AUC, respectively).

A pilot study was conducted to investigate the kinetics of recovery of GTN-induced exhaled NO response in the post-operative period. Figure 3 depicts such an example in a ventilated lung transplant recipient. Although basal exhaled NO increased shortly after reperfusion ( 4 to 24 hours), GTN remained without effect during this period and only partially recovered at 36 hours after the operation.

To determine whether exhaled NO dysfunction related to donor factors or ischemia-reperfusion (I/R) injury, measurements were made in three acceptable donors and in the recipients after implantation and reperfusion of the lungs using the same analyzer and same ventilation setting. Figure $4 \mathrm{a}$ demonstrates a representative pattern of exhaled $\mathrm{NO}$ in the accepted donors and shows a detectable basal exhaled NO and a
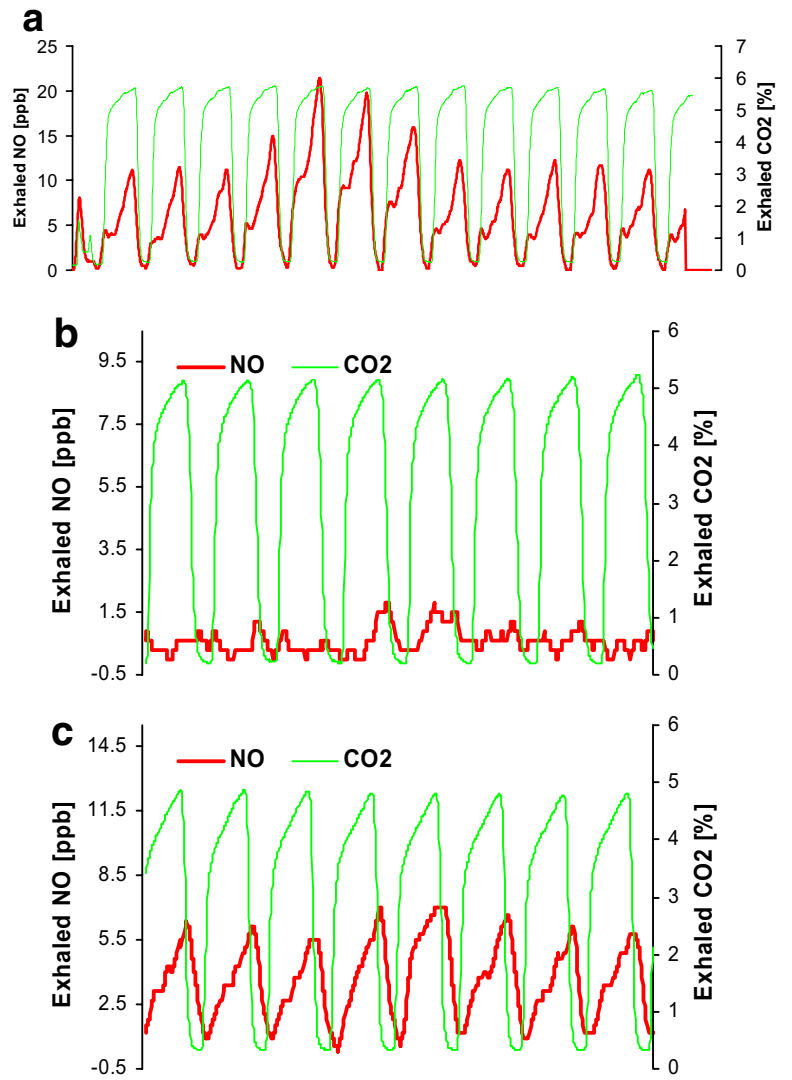

Figure 1. Representative traces of gas-phase nitric oxide (NO) and carbon dioxide $\left(\mathrm{CO}_{2}\right)$ in response to intravenous administration of a $3-\mu \mathrm{g} / \mathrm{kg}$ bolus of nitroglycerin in patients undergoing open heart surgery and lung transplantation. (a) Characteristic responses in a control patient before cardiopulmonary bypass. Panels (b) and (c) depict endogenous and GTN-induced changes in representative lung transplant recipients with either reduced (b) or preserved (c) endogenous exhaled NO levels.
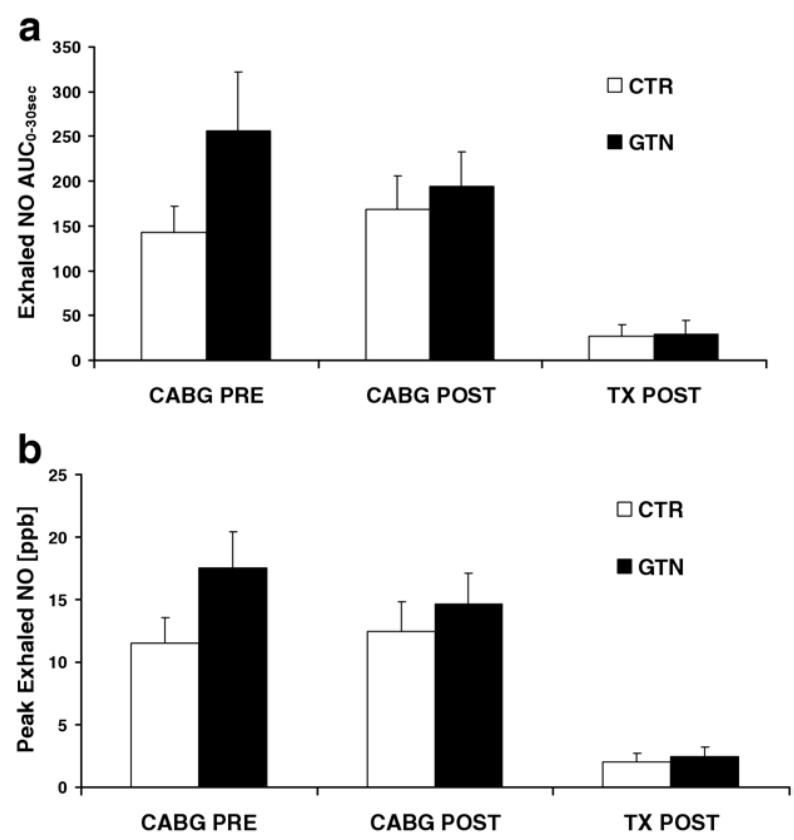

Figure 2. Endogenous (CTR) and nitroglycerin (GTN)-induced increase in exhaled NO with regard to (a) area under the curve for 30 seconds and (b) peak levels in patients undergoing open heart surgery before (CABG PRE) and after cardiopulmonary bypass (CABG POST) and in lung transplant recipients after reperfusion (TX POST). Data are expressed as mean \pm SEM for CABG $(n=10)$ and transplant $(n=10)$.

characteristic rapid rise after a breath-holding maneuver. Figure $4 \mathrm{~b}$ depicts the donor response to GTN and shows a response quite similar to those seen in control cardiac patients. Figure $4 \mathrm{c}$ and $\mathrm{d}$ exhibits the situation after reperfusion in the recipient and shows that basal exhaled NO and breath-hold NO was reduced and that GTN-induced exhaled NO response was practically absent.

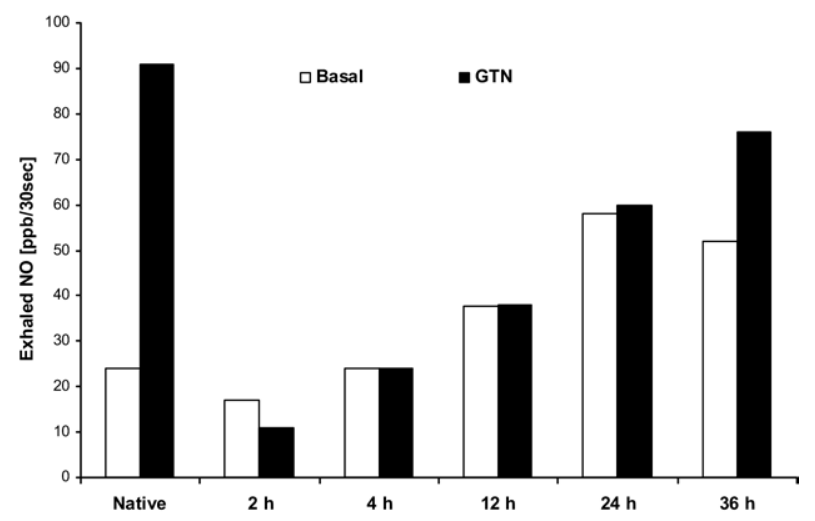

Figure 3. Kinetics of recovery of endogenous (basal) and nitroglycerin (GTN)-induced exhaled NO in a ventilated lung transplant recipient after reperfusion. Note increased basal exhaled NO for 2 to 24 hours after reperfusion, but detectable further response to GTN only at 36 hours. As a reference, exhaled NO in the recipient's native lungs (primary pulmonary hypertension) prior to excision is also indicated (native). 
a

Basal

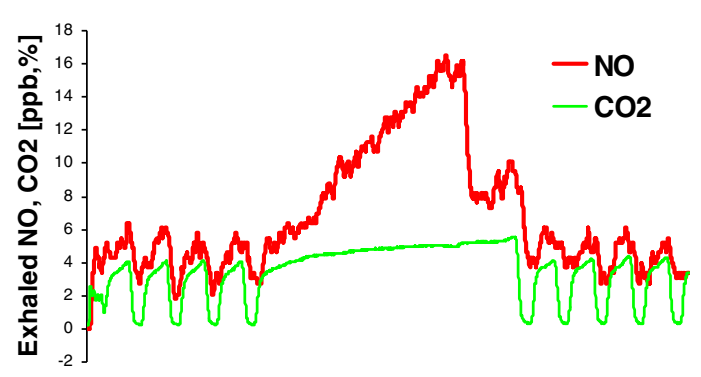

b

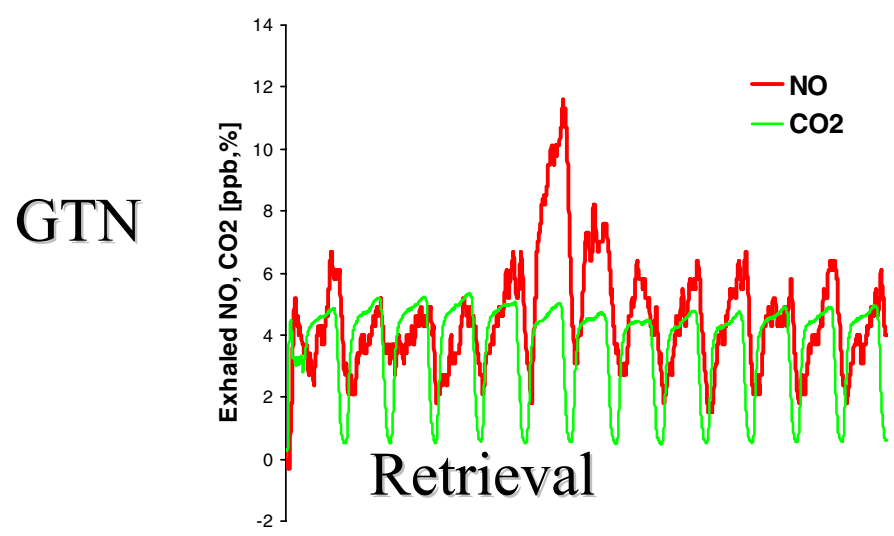

C
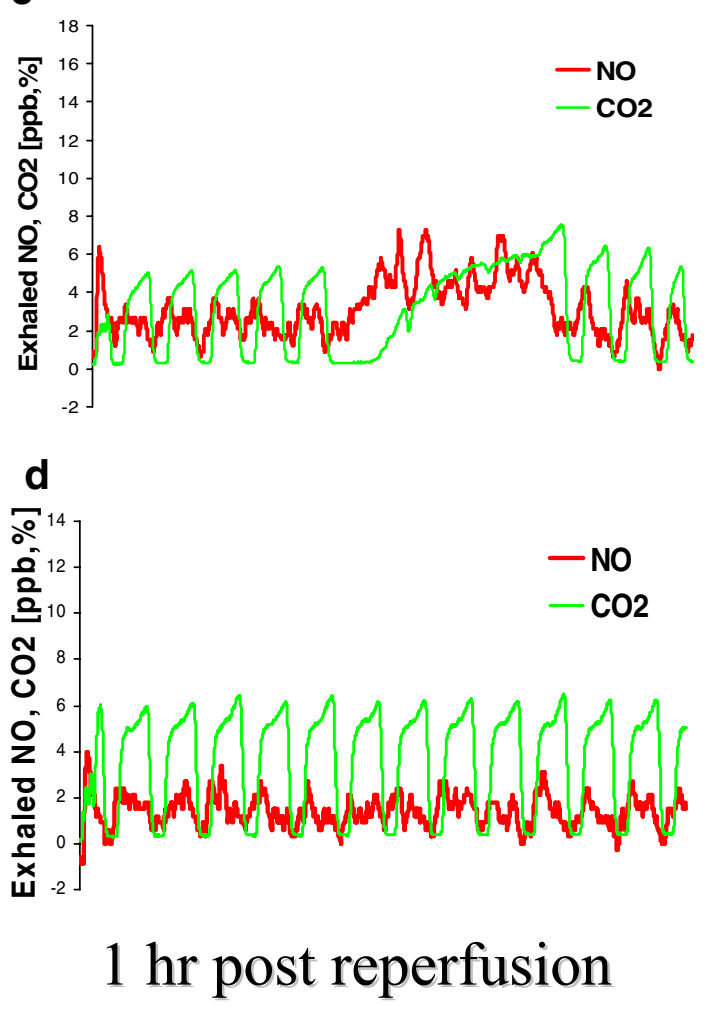

Figure 4. Representative exhaled $\mathrm{NO}$ and $\mathrm{CO}_{2}$ traces before and after lung transplantation. Exhaled $\mathrm{NO}$ was measured under basal conditions before and after a breath-holding maneuver (a) or after administration of intravenous nitroglycerin (GTN, 3- $\mu \mathrm{g} / \mathrm{kg}$ bolus) (b) in a mechanically ventilated donor. The measurements were performed at a distant hospital with standardized ventilation utilizing a portable chemiluminescence NO analyzer (Logan Research, Inc.). Note characteristic exhaled NO tidal traces and increase after breath-holding and the GTN bolus. Right-side panels depict identical measurements after implantation and reperfusion in the recipient. Also note reduced endogenous (basal) exhaled N0 and absence of GTN response.

\section{DISCUSSION}

This study has demonstrated for the first time a profound and selective impairment in pulmonary metabolism of GTN to increase exhaled NO in the setting of prolonged and complete lung ischemia in humans. When compared with transient and partial ischemia, such as that occurring during cardiopulmonary bypass, it appears that ischemia has a graded effect on exhaled NO pathways. Furthermore, GTN-induced exhaled NO seems to be more severely affected than endogenous exhaled NO. Our study also suggests that both endogenous- and exogenous-stimulus (GTN)-induced NO pathways can be preserved after brain death in potential multiple-organ donors and that the observed attenuation of NO pathways in the early post-operative period is the effect of procurement/preservation/implantation/reperfusion.

There are multiple dynamic pulmonary and systemic inflammatory mechanisms that may influence exhaled NO during lung transplantation. I/R injury and surgeryinduced systemic inflammatory response are associated with a complicated picture of NOS expression and NO generation and consumption. Therefore, actual NO concentrations will be different according to the dynamically changing cytokine environment, the nature of microvascular and airway inflammation, neutrophil activation, concomitant production of reactive oxygen species, and acidity in the immediate environment of endothelial and airway epithelial cells. ${ }^{26}$

This study confirms and extends our previous hypothesis that exhaled NO may be considered as a negative biomarker of acute lung injury. ${ }^{21,26}$ Indeed, studies of various cellular and animal models suggested that the dominant reaction of $\mathrm{NO}$ in the setting of oxidative stress and ischemia-reperfusion injury is consumption of NO. ${ }^{8,27,28}$ The potential clinical relevance of this phenomenon to molecular diagnostics of lung injury at the bedside has been implicated by demonstrations that basal exhaled NO is attenuated to differing degrees in bypass surgery, acute respiratory distress syndrome (ARDS) and lung transplantation. ${ }^{18,19,29-32}$ Because basal exhaled NO mainly reflects the relatively large amount of NO release from the airway compartment, ${ }^{33,34}$ we speculated that such changes in exhaled 
NO might represent airway epithelial cell dysfunction and/or oxidative stress in the vicinity of these cells. ${ }^{24,26}$

To further investigate the fate of NO pathways in the microvascular lung compartment, one can deliver exogenous NO to the pulmonary circulation and monitor evolution of this NO in exhaled breath. ${ }^{18,23,35-37}$ We have suggested that GTN-induced exhaled NO might be a useful tool to monitor metabolic function of the pulmonary microvasculature. This proposed test has numerous clinical, diagnostic and mechanistic advantages and could compliment the current clinical diagnostic efforts. It is clinically practical as the doses administered are routinely used in anesthesia and intensive-care settings. The detection system is entirely noninvasive. There is good theoretical and biochemical foundation for bioconversion of nitroglycerin to $\mathrm{NO}$ involving cellular redox mechanism, thus linking oxidative stress to alterations of GTN metabolism and NO consumption. ${ }^{38,39}$

Along these lines, we and others have demonstrated that routine cardiopulmonary bypass alters GTN metabolism to evoke exhaled NO. ${ }^{24,32,40}$ The major novel finding of the current study is the complete loss of GTN metabolism to produce exhaled NO in lungs subjected to prolonged ischemia and reperfusion during lung transplantation. This phenomenon may be explained by at least two major mechanisms: loss of enzyme activity and inactivation of NO.

Although the enzyme responsible for conversion of GTN to NO remains to be identified, the reaction appears to involve redox processes, particularly reduced cellular sulfhydrils. ${ }^{41}$ Because oxidant stress associated with I/R might have a significant influence on this enzyme system, loss of the GTN-converting enzyme activity could explain alterations in GTN-induced exhaled NO in lung transplant recipients.

Alternatively, NO produced by the activity of GTNconverting enzyme could be subjected to oxidant stress and consumption by fluid-phase reactions. This could result in a free radical reaction of $\mathrm{NO}$ with superoxide anion to produce peroxynitrite, a mechanism implicated in acute lung injury. ${ }^{42}$ Our findings that GTNinduced increase in exhaled $\mathrm{NO}$ is lost, even in patients whose endogenous responses to produce exhaled $\mathrm{NO}$ remains normal, suggests that altered GTN metabolism probably represents vascular mechanisms rather than events in airway epithelial cells or interactions of $\mathrm{NO}$ in the gas phase. Attenuation of GTN-induced responses by oxidant stress has been reported before and in fact has been postulated as the underlying mechanism of both primary and secondary nitrate tolerance. ${ }^{43,44}$ Our study has extended these observations and suggests that monitoring GTN-induced exhaled NO could be used to assess primary and secondary nitrate tolerance in the clinical setting. ${ }^{37}$
Although these observations clearly demonstrate pulmonary microvascular injury during lung transplantation, the exact molecular mechanisms, the implications to microvascular reactivity and endothelial permeability, and overall clinical relevance remain to be uncovered. Our working hypothesis is that increased oxidative stress is responsible for NO attenuation and the activity of NO pathways could be restored by appropriate anti-oxidant therapy. We are currently testing this hypothesis in model systems and in a clinical study using $N$-acetylcysteine.

We have suggested that decreased exhaled NO after implantation could be the result of reperfusion injury, but brain death in the donor or preservation injury cannot be ruled out. ${ }^{18}$ Our study has provided initial evidence that accepted donors may have quasi-normal exhaled NO and that their responses to intravenous GTN do not seem to be different from those of control patients. It will be of interest to see if there are characteristic changes in exhaled NO in unacceptable lung donors.

In conclusion, we have demonstrated for the first time the dynamic alterations in NO pathways (as reflected in exhaled NO arising from two pulmonary compartments) that may occur during the operative phase of the transplantation process. Obtaining quantitative data on one of the most powerful regulators of the inflammatory processes with relative ease and in real time at the bedside could be considered major progress. The data suggest that the current practice of lung transplantation is associated with biochemical evidence of microvascular and airway epithelial dysfunction in the immediate post-operative period. Further studies are required to fully elucidate the details and clinical relevance of this phenomenon and the diagnostic value of exhaled NO measurements in lung transplantation.

The authors thank the consultants, junior doctors and theatre staff of Harefield Hospital and transplant coordinators for support and helpful discussions. Dr Marczin was recipient of the MRC Clinician Scientist Fellowship during these studies.

\section{REFERENCES}

1. Christie JD, Bavaria JE, Palevsky HI, et al. Primary graft failure following lung transplantation. Chest 1998;114:51-60.

2. Gammie JS, Cheul LJ, Pham SM, et al. Cardiopulmonary bypass is associated with early allograft dysfunction but not death after double-lung transplantation. J Thorac Cardiovasc Surg 1998;115: $990-7$.

3. Khan SU, Salloum J, O'Donovan PB, et al. Acute pulmonary edema after lung transplantation: the pulmonary reimplantation response. Chest 1999;116:187-94.

4. Pinsky DJ. The vascular biology of heart and lung preservation for transplantation. Thromb Haemost 1995;74:58-65.

5. Naka Y, Toda K, Kayano K, et al. Failure to express the P-selectin gene or P-selectin blockade confers early pulmonary protection after lung ischemia or transplantation. Proc Natl Acad Sci USA 1997;94:757-61. 
6. Barnes PJ, Belvisi MG. Nitric oxide and lung disease. Thorax 1993; $48: 1034-43$.

7. Marczin N, Royston D. Nitric oxide as mediator, marker and modulator of microvascular damage in ARDS. $\mathrm{Br} \mathrm{J}$ Anaesth 2001;87:179-83.

8. Pinsky DJ, Naka Y, Chowdhury NC, et al. The nitric oxide/cyclic GMP pathway in organ transplantation: critical role in successful lung preservation. Proc Natl Acad Sci USA 1994;91:12086-90.

9. Naka Y, Chowdhury NC, Liao H, et al. Enhanced preservation of orthotopically transplanted rat lungs by nitroglycerin but not hydralazine. Requirement for graft vascular homeostasis beyond harvest vasodilation. Circ Res 1995;76:900-6.

10. Naka Y, Chowdhury NC, Oz MC, et al. Nitroglycerin maintains graft vascular homeostasis and enhances preservation in an orthotopic rat lung transplant model. J Thorac Cardiovasc Surg 1995;109:206-10.

11. Egan TM, Hoffmann SC, Sevala M, Sadoff JD, Schlidt SA. Nitroglycerin reperfusion reduces ischemia-reperfusion injury in nonheart-beating donor lungs. J Heart Lung Transplant 2006;25: $110-9$.

12. Gomez CB, del Valle HF, Bertolotti B, et al. Effects of short-term inhaled nitric oxide on interleukin-8 release after single-lung transplantation in pigs. J Heart Lung Transplant 2005;24:714-22.

13. Lepore JJ, Dec GW, Zapol MW, Bloch KD, Semigran MJ. Combined administration of intravenous dipyridamole and inhaled nitric oxide to assess reversibility of pulmonary arterial hypertension in potential cardiac transplant recipients. J Heart Lung Transplant 2005;24:1950-6.

14. Naka Y, Roy DK, Smerling AJ, et al. Inhaled nitric oxide fails to confer the pulmonary protection provided by distal stimulation of the nitric oxide pathway at the level of cyclic guanosine monophosphate. J Thorac Cardiovasc Surg 1995;110:1434-40.

15. Meade M, Granton JT, Matte-Martyn A, et al. A randomized trial of inhaled nitric oxide to prevent reperfusion injury following lung transplantation. J Heart Lung Transplant 2001;20:254-5.

16. Kharitonov S, Alving K, Barnes PJ. Exhaled and nasal nitric oxide measurements: recommendations. The European Respiratory Society Task Force. Eur Respir J 1997;10:1683-93.

17. ATS/ERS recommendations for standardized procedures for the online and offline measurement of exhaled lower respiratory nitric oxide and nasal nitric oxide, 2005. Am J Respir Crit Care Med 2005;171:912-30.

18. Marczin N, Riedel B, Gal J, Polak J, Yacoub M. Exhaled nitric oxide during lung transplantation. Lancet 1997;350:1681-2.

19. Brett SJ, Evans TW. Measurement of endogenous nitric oxide in the lungs of patients with the acute respiratory distress syndrome. Am J Respir Crit Care Med 1998;157:993-7.

20. Carlin RE, Ferrario L, Boyd JT, et al. Determinants of nitric oxide in exhaled gas in the isolated rabbit lung. Am J Respir Crit Care Med 1997;155:922-7.

21. Silkoff PE, Erzurum SC, Lundberg JO, et al. ATS workshop proceedings: exhaled nitric oxide and nitric oxide oxidative metabolism in exhaled breath condensate. Proc Am Thorac Soc 2006:3:131- 45 .

22. Dweik RA, Laskowski D, Abu-Soud HM, et al. Nitric oxide synthesis in the lung. Regulation by oxygen through a kinetic mechanism. J Clin Invest 1998;101:660-6.

23. Marczin N, Riedel B, Royston D, Yacoub M. Intravenous nitrate vasodilators and exhaled nitric oxide. Lancet 1997;349:1742.

24. Kovesi T, Royston D, Yacoub M, Marczin N. Basal and nitroglycerin-induced exhaled nitric oxide before and after cardiac surgery with cardiopulmonary bypass. Br J Anaesth 2003;90:608-16.

25. Marczin N, Kovesi T, Royston D. Exhaled nitric oxide as a marker of lung injury in coronary artery bypass surgery. Br J Anaesth 2003;90:101-4.
26. Marczin N. The biology of exhaled nitric oxide (NO) in ischemia-reperfusion-induced lung injury: a tale of dynamism of NO production and consumption. Vasc Pharmacol 2005; 43 : 415-24.

27. Marczin N, Ryan US, Catravas JD. Effects of oxidant stress on endothelium-derived relaxing factor-induced and nitrovasodilator-induced cGMP accumulation in vascular cells in culture. Circ Res 1992;70:326-40.

28. Morita $\mathrm{K}$, Ihnken $\mathrm{K}$, Buckberg GD, Ignarro LJ. Oxidative insult associated with hyperoxic cardiopulmonary bypass in the infantile heart and lung. Jpn Circ J 1996;60:355-63.

29. Beghetti M, Silkoff PE, Caramori M, et al. Decreased exhaled nitric oxide may be a marker of cardiopulmonary bypass-induced injury. Ann Thorac Surg 1998;66:532-4.

30. Ishibe $\mathrm{Y}$, Liu R, Hirosawa J, et al. Exhaled nitric oxide level decreases after cardiopulmonary bypass in adult patients. Crit Care Med 2000;28:3823-7.

31. Cuthbertson BH, Stott SA, Webster NR. Exhaled nitric oxide as a marker of lung injury in coronary artery bypass surgery. Br J Anaesth 2002;89:247-50.

32. Tornberg DC, Angdin M, Settergen G, et al. Exhaled nitric oxide before and after cardiac surgery with cardiopulmonary bypassresponse to acetylcholine and nitroglycerin. Br J Anaesth 2005; 94:174-80.

33. Sartori C, Lepori M, Busch T, et al. Exhaled nitric oxide does not provide a marker of vascular endothelial function in healthy humans. Am J Respir Crit Care Med 1999;160:879-82.

34. Marczin N. Exhaled nitric oxide and cardiac surgery with extracorporeal circulation. J Thorac Cardiovasc Surg 2003;126:1673-4.

35. Persson MG, Agvald P, Gustafsson LE. Detection of nitric oxide in exhaled air during administration of nitroglycerin in vivo. $\mathrm{Br} \mathrm{J}$ Pharmacol 1994;111:825-8.

36. Cederqvist B, Persson MG, Gustafsson LE. Direct demonstration of NO formation in vivo from organic nitrites and nitrates, and correlation to effects on blood pressure and to in vitro effects. Biochem Pharmacol 1994;47:1047-53.

37. Husain M, Adrie C, Ichinose F, Kavosi M, Zapol WM. Exhaled nitric oxide as a marker for organic nitrate tolerance. Circulation 1994;89:2498-2502.

38. Hansson GK, Jornvall H, Lindahl SG. [The Nobel Prize 1998 in physiology or medicine. Nitrogen oxide as a signal molecule in the cardiovascular system.] Ugeskr Laeger 1998;160:7571-8.

39. Fung HL. Biochemical mechanism of nitroglycerin action and tolerance: is this old mystery solved? Annu Rev Pharmacol Toxicol 2004; 44:67-85.

40. Kovesi T, Royston D, Yacoub MY, Marczin N. Exhaled nitric oxide in human lung ischaemia-reperfusion. In: Marczin $\mathrm{N}$, Kharitonov SA, Yacoub MH, Barnes PJ, editors. Disease markers in exhaled breath. Lung biology in health and disease 170. New York: Marcel Dekker; 2003:259-79.

41. Fung HL, Chung SJ, Bauer JA, Chong S, Kowaluk EA. Biochemical mechanism of organic nitrate action. Am J Cardiol 1992;70: $4 \mathrm{~B}-10 \mathrm{~B}$.

42. Haddad IY, Pataki G, Hu P, Galliani C, Beckman JS, Matalon S. Quantitation of nitrotyrosine levels in lung sections of patients and animals with acute lung injury. J Clin Invest 1994;94: 2407-13.

43. Munzel T, Harrison DG. Evidence for a role of oxygen-derived free radicals and protein kinase $\mathrm{C}$ in nitrate tolerance. J Mol Med 1997;75:891-900.

44. Dikalov S, Fink B, Skatchkov M, Stalleicken D, Bassenge E. Formation of reactive oxygen species by pentaerithrityltetranitrate and glyceryl trinitrate in vitro and development of nitrate tolerance. J Pharmacol Exp Ther 1998;286:938-44. 